\title{
POR UMA CONCEPÇÃO FILOSÓFICA PARA O ENSINO DE FILOSOFIA
}

\author{
Francisco Kleber Farias ${ }^{1}$ \\ Gildásio Guedes Fernandes ${ }^{2}$
}

\begin{abstract}
Resumo
O presente artigo tem como objetivo pensar sobre a necessidade de uma concepção filosófica para a disciplina de filosofia no Ensino Médio. Tendo em vista que, dentre os questionamentos que surgem quando se pensa em tal ensino, um dos mais recorrentes, sem sombra de dúvidas nenhuma, é: o que é filosofia? exige-se dessa forma uma concepção filosófica que dê conta de responder a tal inquietação e possa ser a base do ensino da disciplina filosófica, levando assim os alunos ao próprio ato ou processo do filosofar. A pesquisa realizada é totalmente bibliográfica e, para tal, se faz uso de textos impressos e retirados da internet. A partir desta literatura faz-se uma análise crítica dos principais conceitos abordados pelos teóricos que discutem atualmente acerca desse tema. Por fim, apoiado na concepção filosófica de Karl Popper, conclui-se que a filosofia em sua essência é necessariamente crítica e, portanto, assim também deve ser o seu ensino no que diz respeito à mesma enquanto disciplina escolar.
\end{abstract}

Palavras chaves: ensino, filosofia, concepção filosófica, criticidade.

\section{FOR A PHILOSOPHICAL CONCEPTION FOR THE TEACHING OF PHILOSOPHY}

\begin{abstract}
This article aims to think about the need for a philosophical conception for the discipline of philosophy in high school. Bearing in mind that, among the questions that arise when thinking about such teaching, one of the most recurrent, without any doubt, is: what is philosophy? in this way, a philosophical conception is required that is capable of responding to such uneasiness and may be the basis for the teaching of the philosophical discipline, thus leading students to the very act or process of philosophizing. The research carried out is completely bibliographic and, for this, it uses printed texts and taken from the internet. From this literature a critical analysis is made of the main concepts addressed by theorists who currently discuss this topic. Finally, supported by the philosophical conception of Karl Popper, it is concluded that philosophy in its essence is necessarily critical and therefore, so should their teaching with regard to the same school as a discipline.
\end{abstract}

Keywords: teaching, philosophy, philosophical conception, criticality.

\section{$1 \quad$ Introdução}

O ensino de filosofia por muitas vezes é deixado de lado nos grandes debates que ocupam o cenário filosófico, temas como por exemplo a política, a ética, a estética, o conhecimento, a ciência e etc., são os mais preferidos daqueles que se lançam a este tipo de discussão. De nossa parte consideramos de muita importância pensar este lado quase esquecido da filosofia.

1 Licenciado em Filosofia pela Universidade Federal do Piauí - UFPI. Mestrando no Programa de Mestrado Profissional em Filosofia (PROF-FILO) pela Universidade Federal do Piaú - UFPI. E-mail: marcusyasmimclara@gmail.com.

2 Professor titular da UFPI. Doutor em Educação pela UFC. Mestre em Matemática Aplicada pela UNICAMP. Graduado em Licenciatura Plena pela UFPI. Professor e orientador no PROF-FILO pela UFPI. 
Em primeiro lugar, segundo alguns teóricos, para se falar sobre o ensino de filosofia se faz necessário, antes de tudo, fazer as seguintes perguntas: qual filosofia ensinar? Como ensiná-la? E o que é filosofia? É o caso de Aspis (2004, p. 306) que em seu artigo sobre o professor de filosofia e o ensino desta disciplina no nível médio como uma experiência filosófica afirma que, se o professor de filosofia começar sua prática docente com tais questionamentos, certamente terá um bom começo.

É importante que tais questionamentos pairem na mente dos professores, ou mesmo como aconselha a autora supracitada, sobre aqueles que ainda estão pensando em dar aulas de filosofia, pois desta forma estariam problematizando sua atividade, ou seja, transformando-a em um problema filosófico, já que, segundo a mesma autora, não se pode separar o ensino de filosofia do exercício do filosofar.

Supomos que se no ensino de filosofia o professor não o pode fazê-lo de outra forma que não seja por meio de um processo que se mostre filosofado, é salutar também desconfiar que neste particular, como afirma Cerletti (2009, p. 12), qualquer que seja a resposta dada ao problema do que significa aprender filosofia, ela estará de certa forma mediada por uma concepção que se tenha da filosofia e de seus traços característicos.

Diante do exposto acima afirmamos que o objetivo desse trabalho é pensar a necessidade de uma concepção filosófica que possa ser este fator mediador para o ensino de filosofia no nível médio. No entanto, não temos a intenção de colocar nossa ideia como definitiva, mas sim como uma possibilidade para auxiliar os professores nesta árdua tarefa que é ensinar filosofia para jovens e adolescentes.

\section{O problema do ensino de filosofia no Brasil}

O ensino da filosofia no Brasil remonta ao século XVI, mais precisamente ao período colonial com a chegada dos padres jesuítas. Estes tinham a missão de educar e catequizar os colonos. Dessa maneira podemos afirmar que no início tal ensino estava envolto por interesses religiosos. Santos (2016) ressalta que uma das mais notáveis características desse ensino era uma forte defesa da ortodoxia e dogmas católicos, e mais, que tal fato se dava como que sendo uma espécie de resposta à reforma protestante.

Os jesuítas exerceram uma hegemonia de mais de duzentos anos sobre a educação brasileira até serem expulsos pelo Marquês de Pombal. Sobre este período não podemos afirmar

\begin{tabular}{|c|c|c|c|c|}
\hline Qenista Dialectus & Ano 9 & n. 20 & Outubro - Novembro 2020 & p. $43-55$ \\
\hline
\end{tabular}


que o ensino de filosofia teve algo de relevante que pudéssemos considerar como avanço, ao contrário, houve uma implementação de uma cultura livresca e de forte cunho ideológico.

A este respeito esclarece Rocha (2016, p. 201) que a educação jesuítica “em conformidade com a visão religiosa do Concílio de Trento acabava por difundir dentro dos Colégios e Universidades uma educação que salvaguardasse a fé católica, tornando o ensino de filosofia um instrumento de firmação da mesma".

Observa-se neste ponto que o ensino de filosofia implantado pelos jesuítas carecia de espírito crítico, convertendo-se, quando muito, em mera reprodução do pensamento produzido na Europa, fato que se consolidou nos períodos históricos que sucederam ao período colonial, ou seja, tanto no Brasil imperial quanto no republicano.

Um exemplo disso podemos encontrar em César (2012, p. 06), uando a autora, se referindo à ditadura militar, firma que, "percebe-se que o pensar crítico e transformador que caracteriza a atividade filosófica constituíam uma ameaça à ordem vigente, no sentido de que ele propunha formar consciências que pudessem refletir sobre os problemas reais da sociedade".

Não é nosso objetivo neste trabalho fazer um levantamento histórico sobre o ensino de filosofia no Brasil, mas tomando como ponto de partida o fato do mesmo sofrer desta necessidade de criticidade, apontar esta ausência como o problema primeiro e no entanto permanente do ensino de filosofia no Brasil, merecendo assim a nossa sincera atenção. Ainda segundo esta questão, Rocha (2016, p. 200), com muita luminância, afirma que:

[...] a educação de nível médio, em cada momento histórico brasileiro, sempre se configurou de tal modo a atender melhor cada sistema político-ideológico vigente. Levamos em conta para essa afirmação, a partir das leituras realizadas, a importância que os governantes deram à educação, porém, não como requisito de formação críticoemancipatória e política, mas como elemento para difundir ideologias, assim como instrumento de sustentação das ordens socioeconômicas que estiveram presentes no país desde o período colonial.

O ensino de filosofia dessa forma sempre foi posto como um meio para se chegar a objetivos outros referentes à ordem vigente e quando não foi dessa forma o mesmo era simplesmente retirado do currículo escolar, pois representava uma ameaça para quem detinha o poder.

O pensar de forma filosófica nos convida a suspeitar daquilo que é imediatamente dado, daquilo que nos apresentam como verdadeiro e inquestionável, fazendo assim com que até mesmo o que julgamos ser a nossa base de sustentação mais segura para nossas opiniões

\begin{tabular}{|c|c|c|c|c|}
\hline Qevista Dialectus & Ano 9 & n. 20 & Outubro - Novembro 2020 & p. $43-55$ \\
\hline
\end{tabular}


seja investigado e careça de respostas mais firmes e sólidas. Definitivamente podemos dizer que qualquer ordem estabelecida não desejará por certo que tal coisa lhes sobrevenham.

Dessa forma concordamos com o que disse César acima, ou seja, que o pensar crítico e transformador caracteriza a atividade filosófica, e mais ainda, que é justamente a atividade filosófica, enquanto crítica, que potencializa a transformação, primeiramente de nós mesmos, depois da realidade que nos cerca e pede pela nossa intervenção.

Concordamos também e de igual modo com o alerta que Rocha (2016) nos fez de que a importância dada à filosofia neste país, enquanto disciplina escolar, não foi a de uma formação crítica e autônoma por parte dos alunos, mas sim a de um meio de difundirem suas ideologias. Pensamos, todavia, que tal situação exige dos professores desta disciplina uma postura, uma atitude frente a seus alunos em sala de aula, e que esta seja filosófica.

\section{A importância de uma concepção filosófica}

O que esperar então de um professor de filosofia frente a seus alunos em uma sala de aula? Que ministre aulas de filosofia! E como se faz isso? Cremos que esta não é uma questão simples, ao contrário, é complexa, e como tal exige uma resposta igualmente complexa.

Em primeiro lugar é necessário entender o que significa ensinar filosofia. Cerletti (2009) chama a nossa atenção para este detalhe e ressalta que aquela resposta de que ensinar filosofia significa transmitir algum conteúdo é o mesmo que deixar o questionamento sem resposta, pois dessa forma o que se faz é somente um deslocamento do mesmo, pois então teríamos que lidar com duas outras questões, sendo estas no que diz respeito ao que significa os termos transmitir e conteúdo, do ponto de vista da filosofia.

Ainda segundo o autor supracitado é necessário, no que toca ao ensino de filosofia, que se tenha um ponto de partida, e que este seja uma concepção filosófica. Esta concepção da parte de quem vai ensinar, ou seja, do professor de filosofia, é então muito importante, já que isto o leva a se perguntar e buscar uma resposta para a questão do que é a filosofia e, por consequência, o que é ensinar filosofia.

Cerletti (2009, p. 14) nos esclarece a importância desses questionamentos feitos acima afirmando que, “as interrogações ‘que é ensinar filosofia?' e ‘que é filosofia?' mantêm então relação direta que enlaça aspectos essenciais da filosofia e do filosofar". Isso significa, em outras palavras, que para o autor o professor de filosofia, ao fazer assim, não se separa do

\begin{tabular}{|c|c|c|c|c|}
\hline Qevista Dialectus & Ano 9 & n. 20 & Outubro - Novembro 2020 & p. $43-55$ \\
\hline
\end{tabular}


filósofo que é enquanto assume para si a tarefa de ensinar filosofia, ou seja, deve ensinar filosofia, sobretudo, filosofando.

Outros autores também concordam com esta mesma linha de pensamento não vendo como separar a filosofia do próprio ato do filosofar. Não existe então algo que podemos dar o nome de filosofia e outro que separadamente e distinto possa atender pelo nome de processo filosofante. Sobre este particular Aspis (2004, p. 308) nos alerta que

\begin{abstract}
Entendemos, então, que não é possível desunir filosofia de filosofar pois os dois são uma mesma coisa. $\mathrm{O}$ filosofar é uma disciplina no pensamento que ao ser operada vai produzindo filosofia e a filosofia é a própria matéria que gera o filosofar. São indissociáveis. A matéria filosofia separada do ato de filosofar é matéria morta, recheio de livro de estante.
\end{abstract}

Para a autora acima mencionada não existe o dilema dualístico filosofia ou filosofar. Em seu artigo a mesma dá uma resposta para a questão do que é a filosofia afirmando que esta é produção de conceitos, e que tais conceitos se dão por meio do filosofar. Dessa forma, entendemos que o chamado ponto de partida, a dita concepção filosófica da qual falamos acima fica evidente nas linhas escritas pela autora.

Um outro teórico que concorda com Aspis que filosofia é produção de conceitos, é seu mestre, Sílvio Gallo. O mesmo em seu livro intitulado Metodologia do ensino de filosofia: uma didática para o ensino médio, ao analisar a obra $O$ que é a filosofia, de Deleuze e Guattari, afirma que a filosofia cria conceitos e propõe então uma forma de lidar com estes conceitos percorrendo o caminho de volta até chegar aos problemas que os originaram (GALLO, 2012, p.80).

Gallo chama o procedimento descrito acima de método regressivo, ou seja, que parte do conceito para os problemas que o criou, tal método, ainda segundo o autor, faz parte daquilo que denominou de pedagogia do conceito. É esta pedagogia do conceito proposta pelo autor apenas uma forma de analisar os conceitos, de compreender a maneira como este ou aquele conceito nasceu, não permitindo assim a criação de novos conceitos. Para compreender melhor este ponto vamos recorrer ao próprio Gallo (2012, p. 81) que afirma

[...] para cada conceito, um campo problemático, um conjunto de problemas, um conjunto de mistérios envolvidos em sua criação. Por meio de tal "método regressivo" da pedagogia do conceito, poderíamos descobrir estes mistérios, o que, porém, não nos autorizaria a colocar um método para criação dos conceitos, uma vez que não há método para a criação. 
É instigante pensar que, se para o autor filosofia é criação de conceitos, como então propor para o ensino de filosofia uma metodologia que não seja criadora de conceitos? Tal questionamento é salutar pois o que fica parecendo é que Gallo faz dessa forma uma separação entre o ensino de filosofia e a própria filosofia, ou seja, de um lado estaria a filosofia criando conceitos e de outro o ensino de filosofia analisando de que forma estes conceitos foram criados, porém, sem que possibilite fazer filosofia durante tal ensino, pois não há aí o processo de criação de conceitos. O método regressivo, portanto, não é um método filosófico, porquanto não cria conceitos.

É claro que podemos admitir com muita facilidade que Gallo não afirma que durante o ensino de filosofia não pode haver a criação de conceitos, mas por um outro lado não parece ser a isto que ele se propõe ao lançar o seu método regressivo, uma vez que, para o autor, não há método em filosofia. Dessa forma o que ele propõe não poderia ser um método filosófico por meio do qual os alunos pudessem não somente aprender mas também fazer filosofia. Segundo o autor "o aprendizado é da ordem do acontecimento, daquilo que não pode ser controlado, medido, circunscrito" (GALLO, 2012, p. 88).

O que então quer Gallo ao propor a sua pedagogia do conceito? De nossa parte temos fortes razões para acreditarmos que o que o autor deseja com tal pedagogia é apenas fazer uma provocação, e esta que seja de tal forma que os alunos, na experiência de entender como este ou aquele conceito foi criado, no trato com os problemas que fizeram surgir tais conceitos, possam eles mesmos de alguma forma se despertarem para criar outros conceitos, não por meio da aplicabilidade de um método eficiente, mas a partir da própria experiência do aluno no ato de pensar.

Cabe então responder àquela insinuação levantada acima de que, se para o autor filosofia é criação de conceitos, então estaria ele fazendo uma separação entre filosofia e ensino de filosofia, já que seu método regressivo não permite a criação de conceitos. Para dar esta resposta vamos mais uma vez recorrer a Gallo (2012, p. 92), que muito acertadamente nos explica: "Chegamos aqui à questão crucial: esse contato com o instrumental dos conceitos significa que cada aluno precisará, de fato, construir, criar conceitos? Ou, em outras palavras: cada aluno deverá ser um filósofo, na aula de filosofia? em certa medida, penso que sim”

Dessa forma percebemos claramente que para o autor não existe separação alguma entre filosofia, a partir de sua concepção de filosofia como criação de conceitos, e ensino de filosofia, uma vez que ele mesmo, como vimos acima, afirma que o aluno deve ser em certa medida também um filósofo, uma vez que poderá criar conceitos quando do contato com outros

\begin{tabular}{|c|c|c|c|c|}
\hline Q Rovista Q Dialectus & Ano 9 & n. 20 & Outubro - Novembro 2020 & p. $43-55$ \\
\hline
\end{tabular}


conceitos e os problemas que o originaram por meio de seu método regressivo com sua pedagogia do conceito. Dito isto, passaremos a partir de agora à apresentação de nossa proposta de concepção filosófica para o ensino de filosofia.

\section{$4 \quad$ A filosofia como crítica necessária}

Até aqui vimos que o ensino de filosofia no Brasil desde o seu início com os jesuítas tem sofrido de carência de criticidade. O que temos é uma espécie de enlatado estrangeiro, sobretudo da filosofia produzida na Europa, que é transmitida de forma acrítica apenas para reforçar uma ou outra ideologia de um determinado grupo que está no poder.

Vimos também que um assim chamado ensino de filosofia só é possível se o mesmo partir de uma concepção filosófica que leve os alunos ao próprio ato do filosofar. Neste sentido o professor de filosofia tem papel importantíssimo, pois somente ele, naquele ambiente da sala de aula, pode provocar seus alunos a tal processo filosofante e, por isso mesmo, deve estar consciente não somente de seu trabalho, mas também da forma como realizá-lo. A este respeito, Kohan (2009, p. 38-39) nos adverte que:

[...] o trabalho do cuidado, do pensamento, da filosofia, começa sempre pelo si mesmo; não há como provocar certo efeito no outro se antes não se faz esse trabalho consigo mesmo: como ensinar filosofia desde fora da filosofia? como ensinar a filosofar se não se filosofa? Como aprender filosofia com quem está fora da filosofia?

O autor supracitado nos chama a atenção para este exercício realizado pelo professor de filosofia, a saber, o de começar o trabalho filosófico por si mesmo, se auto examinando, por um motivo que é bastante salutar, o de que o mesmo irá projetar este exame em todos os outros, em cada um de seus alunos, daí a necessidade de começar por si.

Esta atitude de começar com o questionamento por si mesmo e, somente depois, pelos outros, nos faz perceber a filosofia como sendo necessariamente crítica, e isso nos leva automaticamente ao pensamento de que o ensino de filosofia deve ser de igual modo, ou seja, deve levar o aluno ao pensamento crítico. Temos então um ponto de partida, uma concepção filosófica para o ensino de filosofia. Quanto a esta questão, Braga et al. (2014, p. 66) nos falam que:

O educando deve ser conduzido à prática da criticidade e seu pensamento deve ser impulsionado ao exercício da ação do pensar [...] Quem administra o processo ensino-

\begin{tabular}{|l|l|l|l|l|}
\hline Q & Ano 9 italectus & n. 20 & Outubro - Novembro 2020 & p. $43-55$ \\
\hline
\end{tabular}


aprendizagem deve conduzir o modo de fazer, impulsionando o desenvolvimento das potencialidades no educando.

Assim sendo, é necessário compreender que o ensino de filosofia deve ser essencialmente crítico, tendo o professor a tarefa toda especial de administrar este processo e, neste sentido, se faz necessário uma melhor fundamentação acerca disso que chamamos aqui de filosofia crítica e para tal vamos recorrer ao pensamento do filósofo Karl Raimund Popper, que tem uma visão do método filosófico como sendo plenamente possuidor de criticidade no trato das soluções propostas para determinados problemas (PELUSO, 1995, p. 35).

O que determina uma teoria como científica para nosso pensador é o que chamou de refutabilidade, e isto diz respeito a uma característica que se expressa pela capacidade que uma teoria tem ou não de ser testada, ou seja, pela sua testabilidade. Ora, se tal critério é o suficiente para classificar uma teoria como sendo científica, devemos entender que o fato de uma teoria o possuir significa que jamais poderá ser de natureza filosófica, pois as teorias filosóficas não são empiricamente testáveis, logo; a refutabilidade não é característica de uma teoria filosófica. Sendo assim, Popper conclui que uma teoria filosófica não pode ser refutada, em outras palavras, é irrefutável (PELUSO, 1995, p. 33).

$\mathrm{O}$ que se tem em comum entre ciência e filosofia na obra de Karl Popper é a característica da criticidade, para ele a criticidade não é uma característica apenas da filosofia, mas também das ciências, das artes, e das outras formas de conhecimento. E assim sendo, devemos avaliar de outra forma as teorias filosóficas, a saber, pela relação que tais teorias têm com os problemas aos quais se propõem a serem soluções, ou seja, por meio da crítica. E dessa forma, Popper (1978, p. 100), nos fala com muita propriedade que:

\footnotetext{
A crítica é o sangue vital da filosofia, com toda a certeza. Mesmo assim, nós devemos evitar filigramas. Uma crítica minuciosa de questões pontuais, sem um entendimento dos grandes problemas de cosmologia, de conhecimento humano, de ética, e de filosofia política, e sem uma tentativa séria e devotada de solucioná-los, parece-me fatal.
}

As teorias filosóficas, embora não possam ser testadas empiricamente, podem suscitar uma especulação acerca das grandes questões sobre o mundo, inclusive sobre nós enquanto parte desse mundo. O trabalho do filósofo, então, é se propor a esta discussão criticamente e tentar dar respostas a esses problemas (POPPER, 1978, p. 100).

Mas para Popper, essa especulação não deve ser feita da forma como a filosofia acadêmica ou profissional vinha fazendo em sua época, ou seja, por meio de palavras

\begin{tabular}{|c|c|c|c|c|}
\hline Rovista Dialeatus & Ano 9 & n. 20 & Outubro - Novembro 2020 & p. $43-55$ \\
\hline
\end{tabular}


impressionantes, mas que nada acrescentavam e nem muito menos eram compreendidas, para ele o filósofo deve falar de forma clara, o máximo possível. Vejamos o que nos diz Popper (1978, p. 100):

\begin{abstract}
Eu acredito que é o dever de todo intelectual estar consciente da posição privilegiada que ocupa. Ele tem o dever de escrever da maneira mais simples e clara a seu alcance, e da maneira mais civilizada possível; e nunca esquecer quer os grandes problemas que afligem a humanidade e que exigem novas e corajosas, mas pacientes ideias, quer a modéstia de Sócrates, do homem que sabe quão pouco ele sabe.
\end{abstract}

É esse, para o filósofo Popper, o dever de todo filósofo acadêmico, que em vez de se debruçar em escrever de forma ininteligível, que seja simples, claro, que exponha suas ideias de maneira tal que todos compreendam e possam, por sua vez, também formular outras ideias. De nossa parte, também acreditamos que este trabalho pode ser realizado em sala de aula no ensino médio.

Uma última observação sobre a concepção filosófica do filósofo austro-britânico é a de que, para ele, todos os homens e todas as mulheres são filósofos, embora as vezes inconscientes deste fato, e que uns sejam mais que outros, mas todos o são, pois todos conseguem, de alguma forma, formular teorias e criticá-las (POPPER, 1978, p. 92).

Isso faz de nós todos, homens e mulheres, seres que assumem uma atitude tanto diante da vida quanto da morte, e como ele considerava a vida como algo de raro valor! Vale à pena conferir as palavras de Popper (1978, p. 101) a esse respeito, embora seja um pouco delongado, pensamos, vale muito a pena conferir suas palavras:

\footnotetext{
Portanto a vida, seja como for, tem o valor de algo raro; ela é preciosa. Nós somos inclinados a esquecer isto e tentar a vida como algo sem valor, talvez por falta de reflexão, ou talvez porque esta nossa linda terra é, sem dúvida, um pouco superpovoada.

Todos os homens são filósofos, porque de uma maneira ou de outra assumem uma atitude diante da vida e da morte. Existem aqueles que pensam que a vida não tem valor porque um dia termina. Eles deixam de ver que um argumento contrário também pode ser proposto, que se não existisse um fim para a vida, a vida não teria valor; que é, em parte, o perigo sempre presente de perdê-la que nos ajuda a trazer até nós o valor da vida.
}

A concepção filosófica de Popper nos leva a ver a filosofia como altamente crítica, cabendo tal crítica exatamente no exame das soluções dadas a determinados problemas, e mais, nos faz acreditar que a vida pode ser vista de uma outra forma, como tendo um grande valor mesmo diante da morte como possibilidade diária.

\begin{tabular}{|c|c|c|c|c|}
\hline Rovista Dialeatus & Ano 9 & n. 20 & Outubro - Novembro 2020 & p. $43-55$ \\
\hline
\end{tabular}


O professor que adotar esta concepção popperiana de filosofia para ministrar suas aulas não somente estará proporcionando a seus alunos a oportunidade de filosofarem por intermédio da análise crítica das soluções propostas a determinados problemas como também fará seus alunos descobrirem um sentido para a filosofia e para a vida, a saber, o de que a vida tem muito valor e por isso mesmo merece ser bem vivida.

\section{$5 \quad$ Considerações finais}

O ensino de filosofia no Brasil, a julgar pela forma como percebemos ao observar a história do mesmo, carece de criticidade desde a sua fundação. Quando este ensino não era usado apenas para difundir interesses de uma classe que estava e, portanto, queria se manter no poder, o que acontecia era apenas uma reprodução do que se produzia fora, ou então o mesmo era visto como uma ameaça e era retirada a sua obrigatoriedade no currículo escolar, como aconteceu durante a ditadura militar.

É importante que se tenha em mente que para se pensar o ensino de filosofia se faz necessário que se estabeleça um ponto de partida e que este seja uma concepção filosófica que permita que o educando participe do processo do filosofar. O professor neste sentido tem um papel muito importante, pois é ele quem deve administrar o fazer filosófico em sala de aula.

Reconhecemos que a filosofia trabalha com conceitos e os produz, conforme vimos ao citar Sílvio Gallo e sua concepção de pedagogia do conceito com seu método regressivo. Todavia faltou ao Gallo dizer como estes conceitos são produzidos e, apesar dele propor seu método regressivo, o mesmo reconhece que tal método não pode ser considerado um método produtor de conceitos, portanto o julgamos como um método não filosófico.

Sendo então o método proposto por Gallo para o ensino de filosofia um método não filosófico e, portanto, externo à filosofia, nos inquieta a desconfiança da garantia de que o mesmo, uma vez utilizado em sala de aula, levará os alunos à experiência do filosofar. Dessa forma, aceitamos então aquele questionamento citado acima, feito por Kohan: "como aprender filosofia com quem está fora da filosofia?"

Portanto aprender um conceito e a forma como ele foi criado, ao menos para nós, parece ser apenas uma repetição daquele velho problema da educação filosófica brasileira já denunciado aqui, ou em outras palavras, mera reprodução de conteúdo carente de criticidade.

\begin{tabular}{|c|c|c|c|c|}
\hline Revista Dialectus & Ano 9 & n. 20 & Outubro - Novembro 2020 & p. $43-55$ \\
\hline
\end{tabular}


Contrapondo este ponto de vista apresentamos a concepção filosófica de Karl Popper, que nos traz uma visão diferente sobre filosofia, em vez de tentar justificar um método para a atividade ou mesmo para o objeto filosófico, ele afirma que não há método definido em filosofia, mas sim uma forma racional de especular acerca daquilo que nos interessa e que isto é feito de forma crítica, clara e sem arrogância.

Nos chama a atenção a importância que Popper dá aos problemas em sua metodologia teórica, tanto em ciência quanto em filosofia. Para ele, as soluções dadas aos problemas nos levam a outros problemas, e assim, é sempre tensa a linha divisória entre o que sabemos e o que ignoramos, à medida que conhecemos mais, também aumenta o que ignoramos. A este respeito, escreve Magee (1973, p. 40) que:

[...] o fato de que cada nova descoberta nos traz uma série de problemas insuspeitados são notas que caracterizam a metodologia teórica defendida por Popper. Ele compreende que a nossa ignorância cresce com o nosso saber e que, por conseguinte, o número de questões será sempre maior do que o número de respostas.

Neste sentido, cremos, não basta entender os conceitos e os problemas que deram origem a eles, é preciso entender que os conceitos fazem parte de teorias que buscam dar respostas a determinados problemas e, por isso mesmo, segundo Fávero et al. (2019, p. 45), “devem ser permanentemente submetidas à crítica a fim de avaliar seu potencial explicativo".

Aprendemos com isso que a filosofia tem este potencial de perguntar acerca de tudo, de colocar tudo em suspensão para uma nova avaliação e, por este motivo, deve receber uma dedicação toda especial por quem se propõe a conhecer e a explicar algo por meio dela. Aprendemos também com Popper que é melhor sempre ser otimista diante da vida do que pessimista e que, na qualidade de filósofos, que todos somos, segundo ele, devemos procurar formular e criticar teorias, não somente as dos outros, mas, e principalmente, as nossas mesmas.

Concluímos então que se o professor de filosofia encarar sua atividade profissional em sala de aula a partir de uma concepção filosófica que responde à pergunta do que é filosofia, poderá levar a si mesmo e a seus alunos a uma viagem filosofal que começará na primeira aula, sem que se saiba jamais aonde, ou mesmo, se terminará.

\section{Referências}

\begin{tabular}{|c|c|c|c|c|}
\hline Qevista Dialectus & Ano 9 & n. 20 & Outubro - Novembro 2020 & p. $43-55$ \\
\hline
\end{tabular}


ASPIS, Renata Pereira Lima. O professor de filosofia: o ensino de filosofia no ensino médio como experiência filosófica. Cad. Cedes, Campinas, v. 24, n. 64, p. 305-320, set./dez. 2004. Disponível em: http://www.cedes.unicamp.br. Acesso em 14 jun. 2019.

BRAGA, Lélio Favecho; SEVERINO, Antônio Joaquim. Filosofia, educação e formação humana: a busca dos sentidos do fazer educativo. Estação Científica, Macapá, v. 4, n. 2, p. 65 73, jul./dez. 2014. Disponível em: http://periodicos.unifap.br/index.php/estacao. Acesso em 15 jul. 2019.

CERLETTI, A. O ensino de filosofia como problema filosófico/ tradução Ingrid Muller Xavier- Belo Horizonte: Autentica Editora, 2009.

CESAR, Renata Paiva. O ensino de filosofia no brasil. Revista Pandora Brasil, n. 38, p. 111, jan. 2012. ISSN 2175-3318. Disponível em: http://revistapandora.sites.uol.com.br/. Acesso em: 05 jul. 2020.

FÁVERO, Altair Alberto; TONIETO, Carina; POSSEL, Bianca. A resolução de problemas como prática interdisciplinar na educação: uma proposta epistemetodológica. Educação Por Escrito, Porto Alegre, v.9, n.1, p. 41-53, jan./jun. 2018.

GALLO, Sílvio. Metodologia do ensino de filosofia: Uma didática para o ensino médio. Campinas: Papirus, 2012.

JAPIASSU, Hilton Ferreira. Introdução ao pensamento epistemológico, 7 ed. Rio de Janeiro: Francisco Alves, 1992.

KOHAN, Walter Omar. Visões de filosofia: infância. Alea, rio de Janeiro, v. 17/2, p. 216-226, jul./dez. 2015. Disponível em: http://dx.doi.org/10.1590/1517-106x/172-216. Acesso em: 15 jul. 2019.

Filosofia: o paradoxo de aprender e ensinar/ tradução Ingrid Miller Xavier- Belo Horizonte: Autêntica editora, 2009. Coleção ensino de filosofia. ISBN 978-7526-394-5.

MAGEE, Bryan. As ideias de Popper. Tradução: Leônidas Hegenberg, Octanny Silveira da Mota. São Paulo: Cultrix, 1973.

PELUSO, Luís Alberto. A filosofia de Karl Popper: Epistemologia e racionalismo crítico. Campinas: Papirus, 1995.

POPPER, Karl. Conhecimento objetivo. Belo Horizonte: Itatiaia, 1975.

Lógica das ciências sociais. Rio de Janeiro: Tempo Brasileiro, 1978.

Conjecturas e refutações. Coimbra: Almedina, 2003.

\begin{tabular}{|l|l|l|l|l|}
\hline Q & Ano 9 & n. 20 & Outubro - Novembro 2020 & p. $43-55$ \\
\hline
\end{tabular}


ROCHA, Raryson Maciel. A filosofia e o ensino secundário: uma abordagem histórica no contexto da educação brasileira. ANAIS do III Colóquio de Letras da FALE/CUMB, Universidade Federal do Pará, Breves, 18, 10 e 20 fevereiro 2016. ISSN 2358-1131.

SANTOS, Thiago Ferreira dos. Panorama histórico da filosofia no Brasil: da chegada dos jesuítas ao lugar da filosofia na atualidade. Seara Filosófica, n. 12, Inverno, 2016, p. 126-140. 